\title{
ENTRE DOBRADIÇAS E DOBRADURAS: A CONSTRUÇÃO DA PERSONAGEM EM STELLA MANHATTAN, DE SILVIANO SANTIAGO, E BRAZIL, DE JOHN UPDIKE
}

Josane Fátima Barbosa*

RESUMO:

\begin{abstract}
Este trabalho aborda a construção das personagens dobradiças de Stella Manhattan e das personagens dobraduras de Brazil. Essa construção é considerada estratégia de leitura do mundo contemporâneo.

PALAVRAS-CHAVE: personagem dobradiça, personagem dobradura, globalização, diāspora.
\end{abstract}

Tantas foram as mudanças no pensamento operadas ao longo dos séculos que o mundo contemporâneo se encontra permeado por uma espécie de poética da simultaneidade e do fragmento. Inevitavelmente, as expressões culturais, como a literatura, também absorveram e passaram a explorar essa linguagem. A expressão desses elementos se encontra configurada nas páginas de Stella Manhattan e Brazil, relatos cujas personagens, narradores e tramas ilustram, cada um a sua maneira, os movimentos que alinhavam o cotidiano atual.

A escolha de Stella Manhattan e Brazil se deveu aos fatos de serem obras contemporâneas e de se comporem por meio da troca de olhares entre distintas nacionalidades, culturas e etnias. Em Stella Manhattan, o leitor convive com brasileiros exilados em Nova Iorque por diferentes motivos, mantendo o olhar voltado para o Brasil ao mesmo tempo em que são observados pelos norte-americanos e pelas outras personagens. Além disso, as personagens exercem múltiplas sexualidades e se multiplicam umas nas outras dentro da trama, incluindo o leitor nessa rotatividade,

| Mestre em Letras: Literatura, História e Memória Cultural (Área de concentração: Teoria da Literatura), 2004. 


\section{EMTESE}

Belo Horizonte, v. 9, p. I-28I, dez. 2005

tornando-se personagens dobradiças. Em Brazil, o leitor acompanha a trajetória de um casal atado a si mesmo pelo amor, motivo pelo qual empreendem um auto-exilio Brasil adentro. Uma das particularidades desse romance é impressa pelo olhar estrangeiro de um autor norte-americano que, após uma passagem de duas semanas por terras brasileiras, cria a história ambientada aqui, construindo personagens dobraduras, as quais, sendo rígidas, experimentam uma intensa movimentação externa.

Em Brazil, as personagens são caracterizadas de um modo um pouco mais fixo, especialmente quando colocadas em relação às peças moventes de Stella Manhattan. Entra em jogo um outro tipo de mobilidade: a externa, do corpo que percorre diversas paisagens, em lugar da movimentação interna, em que um mesmo corpo se compõe de diversas paisagens. Assim, ao contrário das personagens dobradiças, de Silviano Santiago, John Updike constrói personagens dobraduras. Aqui é preciso evocar a imagem do origami, pensado como um jogo que permite a construção de imagens pela dobradura do papel, a fim de se explicitar uma aproximação pela diferença entre as obras de Updike e Santiago.

No origami, podem ser usadas cores diferentes de papel no desenvolvimento das dobraduras, mas se cria apenas um bicho de cada vez, caracterizando-se um movimento limitado. A mesma fixidez pode ser utilizada para se realizar a caracterização da dobradura em relação às personagens de Brazil, já que elas mantêm as diferenças estabelecidas desde o início do romance. Além da fixidez, observa-se ainda uma dificuldade em se promover uma reciclagem diante de uma estrutura já estabelecida, mas que está ruindo, de acordo com teóricos contemporâneos, como Stuart Hall e Homi Bhabha; por esse ângulo, a multimodulação do sentido não encontra representação nesse romance, visto que os clichês e o preconceito não passam por uma ressignificação; ao contrário, as personagens mudam de cor de pele e, no entanto, as diferenças ainda causam incômodo àqueles com quem Tristão e Isabel se relacionam. Isso somente deixa de ocorrer para o pai da moça, que, estranhamente, não nota diferença alguma na mudança de cor da filha; acha-a um pouco mais bronzeada e atribui tal transformação à exposição da filha ao sol, justificada pelo fato de suas veias conterem gotas de sangue mouro, herdado de sua mãe. Essa atitude de fingimento de cegueira reforça a percepção de que não se promove modificação alguma na estrutura estabelecida no início do relato. 0 que ocorre é que o narrador dobra as personagens envolvendo-as 
em uma intensa movimentação física pela qual mudam constantemente de cenário. Tamanha movimentação, todavia, esbarra num limite que mantém as personagens presas à estrutura social da qual provêm. Nesse sentido, o romance acaba por propor discussões paralelas, sobre o racismo e a prostituição, como formas de complexificar a trama e, portanto, a perspectiva sobre a realidade brasileira. Nesse caso, 0 narrador parece sugerir uma estética da redenção, já que Isabel se prostitui por amor, o que a isenta de dramas de consciência.

Tristão e Isabel de início parecem também se inserir numa rede, devido à referência direta ao romance medieval, do qual derivam seus nomes, com uma pequena adaptação na transposição do nome de Isolda para Isabel. Entretanto a estrutura narrativa permanece basicamente a mesma, pois o casal do romance contemporâneo repete o núcleo da narração em que Tristão e Isolda são fadados a viver em busca um do outro até a morte. Ocorre nessa repetição uma espécie de repelência à mudança e, dessa forma, promove-se o congelamento de uma situação. Outro exemplo se retira do que pode ser chamado de ápice do relato, retratado na troca de cores de pele do casal. Após a transformação, Tristão passa a se sentir mais confiante em sua pele branca enquanto Isabel se torna uma mulher negra sexualmente mais dominadora e agressiva. Isso aponta para a permanência do racismo na atitude das personagens e para a manutenção de estereótipos por parte do narrador. 0 que vem à tona após a leitura do livro é que não ocorre nenhum desafio em relação aos padrões hierarquizantes já estabelecidos entre branco/negro, rico/pobre, homem/mulher. Se não há o desafio, superação muito menos. Permanecem as barras que delimitam os espaços dos pares de opostos e que ao mesmo tempo fixam a hierarquia, como "branca/negro", ou o clichê "branca rica/negro pobre". Essas oposições constituem uma dobradura na qual se manifestam os pares de opostos hierarquizantes e excludentes. Tais dobraduras são constituídas pelos pares opositivos e promovem sua fixação em um modelo em que não se apresentam propostas de mudanças dessa estrutura desigual. Essas personagens permanecem, assim, na dobradura de um mesmo papel que apenas muda de cor, dando uma aparência de transformação, a qual efetivamente não ocorre. Há um arremedo de revolução na mágica transformação do pajé, a qual muda a cor de pele do casal. Todavia logo se constata que as barras continuam delimitando e fixando os espaços pelos quais as personagens se movem. 


\section{EMTESE}

Belo Horizonte, v. 9, p. I-28I, dez. 2005

Ironicamente, por mais que caminhem em busca de um ponto estável, Tristão e Isabel permanecem fora do lugar. 0 auge do desejo de pertencimento de ambos parece se concretizar na troca de pele, o que seria uma última tentativa de se sentirem pertencentes a um ponto, a uma morada. Paradoxalmente, no caminho de volta para casa, continuam esbarrando com os mesmos preconceitos que encontraram na ida: muda apenas a cor do papel, pois a dobradura revela a limitação do movimento. Além disso, ela revela também um certo caráter de exclusividade, visto que, para se construir um origami, apenas um manipulador pode fazer uso do papel. Após a dobradura, encerram-se as possibilidades de desdobramento do objeto construído em outros formatos.

Brazil parece não se preocupar em estabelecer rupturas ou fragmentações que se transformem em brechas que permitam a manipulação do leitor. Encena-se uma certa busca de alternativas, apontada pela peregrinação de Tristão e Isabel, sem rumo, apenas andando. Constata-se que não existe a possibilidade de se propor algo de novo com o intuito de se superarem as diferenças; portanto, é preciso retornar ao ponto de partida, ainda que seja necessário conviver com algumas perdas, como a morte de Tristão. Assim mesmo, há ganhos, pois Isabel retoma um relacionamento harmônico com seu pai e seu tio e poderá reassumir sua posição de mulher entediada, circulando pela alta sociedade. Talvez este seja o jogo - o movimento, a busca, a perda, ainda que se acabe retornando ao ponto inicial. Essa volta parece apontar justamente para a dificuldade de o ser humano contemporâneo estabelecer rupturas com o passado, realizar rearranjos do presente e lançar-se na aventura misteriosa, desconhecida e desafiadora do porvir. Afinal, ter um ponto para onde voltar não deixa de ser o mesmo que ter um porto seguro, mantendo-se a ilusão de se ter certeza sobre algo, de se sentir de novo o chão sob os pés.

Já a personagem Stella Manhattan se oferece como um exercício de movimentação subvertedora da fixidez por se compor através de um jogo de espelhamento em relação às outras personagens. Tal espelhamento ocorre, por exemplo, no modo como elas vivem sua sexualidade; cada uma delas se compõe de camadas de homossexualismo, sadomasoquismo e "perversão", formando uma cadeia de personagens (Stella»Eduardo«Vianna«Paco«Leila«Aníbal «Marcelo) que permutam essas camadas. Assim se faz adequado o emprego da seta bidirecional para se referir a Eduardo"Stella, 
indicando-se um intercâmbio, em lugar de se usar uma barra, significando a exclusão . Dessa forma se percebe uma personagem multimodulada, que resiste à fixidez da interpretação e sobre a qual, por esse motivo, torna-se difícil encerrar uma interpretação que se queira única. A composição dessa personagem dobradiça se remete às placas moventes dos Bichos, de Lygia Clark, que se oferecem à multimodulação e, conseqüentemente, cria-se uma rede pela qual o sentido prolifera e na qual se insere uma reflexão sobre a narrativa como um ensaio no qual se discute a impossibilidade de fixação do sentido, das identidades, das constatações e dos conceitos únicos sobre os acontecimentos. Enfim, percebe-se que a corrente sangüínea de nossa língua gera ondas que abarcam as diversas esferas da vida e da produção do pensamento.

Outro aspecto importante em Stella Manhattan diz respeito à construção da narrativa, que, assim como a das personagens, ocorre de maneira fragmentada e múltipla: os núcleos da trama não se fecham, há sempre um suspense no final de cada capítulo, sendo que o próximo começa com um diferente núcleo narrativo, enfocando outras personagens. Aparentemente, um grupo de personagens não tem nada em comum com o outro; contudo o que acontece é que a proximidade deles está justamente na fragmentação, na hibridez, na multiplicidade e na reversibilidade de faces e modos de expressão.

Num certo momento da narrativa, após o leitor já ter se familiarizado com as personagens, surge um enxerto textual que se configura como um enigma: um escritor escreve, enquanto uma pessoa o vê escrevendo, por trás de seus ombros. Ambas as personagens se incomodam e se interferem: o escritor questiona o olhar do observador e tenta desvendá-10; o observador questiona a escrita e tece comentários sobre ela, às vezes fazendo julgamentos, mentalmente. Silêncios e vozes se entrecruzam, sem necessariamente dialogarem. Mutuamente se interferem e de alguma forma interagem, sem que se identifiquem: o leitor permanece em suspenso, sem saber, afinal, de que se trata.

Stella Manhattan se compõe através de um movimento de remissões cujo resultado é a perda da origem. Essa movimentação de citações aparece camuflada tanto na parte "Começo: o narrador" quanto no dossiê. Nesses trechos, não se localiza uma referência explícita a outros textos, mas se nota uma referência ao processo de construção ficcional (no caso de "Começo: o Narrador") e à ditadura (no caso do 


\section{EMTESE}

Belo Horizonte, v. 9, p. I-28I, dez. 2005

dossiê). Essas remissões configuram a narrativa como um processo de reenvio a si mesma por meio do uso da fragmentação, lançando-a numa rede por cujas malhas circulam a teatralidade, a ditadura, o travestismo, o exilio, indicando as possibilidades de expansão do próprio relato. As personagens, da mesma forma, revestem-se da idéia de multiplicidade, como se fizessem citações umas das outras, no momento em que encenam sua sexualidade, por exemplo. Essa mutabilidade se remete à flexibilidade oferecida pelas placas moventes dos Bichos, que permitem ao observador manipulá-las conforme seu desejo. Assim, essa obra se compõe como um "pré-texto" para os textos compostos pelas personagens do romance.

Assim como os Bichos ganham sentido quando são oferecidos para a interação com o observador, que manipula suas placas móveis, presas por dobradiças, também EduardoöStella pode ser caracterizado como personagem dobradiça: móvel, cambiante, múltiplo, conforme esclarece o autor em entrevista (Santiago, 1991). 0 que Eduardo realiza é uma exploração de seu potencial enquanto ser humano, sem uma preocupação com o uso de máscaras ou a revelação de qualquer essência; o que ocorre é o uso prazeroso do corpo, na descoberta da multiplicidade da vida e de suas possibilidades. É o caso de se admitir juntamente com o autor: "Nós somos vários.", ou seja, as subjetividades são rede e podem se suplementar. Essa atitude também é, de alguma forma, uma resposta ao desmanche que o sujeito vive na atualidade; diante de uma sociedade violenta e consumista, produtora de uma enorme quantidade de lixo, tornase difícil ser otimista e fazer projeções positivas para o futuro. Uma alternativa seria, então, desfrutar o presente, os encontros, ainda que efêmeros, pois se torna cada vez mais complexo estabelecer certezas acerca do dia seguinte.

Há dobradiças nas placas dos Bichos, assim como há dobradiças (e vidraças) articulando as "placas" do texto narrativo. Essas obras colocam em circulação virtualidades de comunicação que não se contentam somente com a linguagem verbal. Convocam diferentes formas de expressão que se proliferam em conteúdos imagéticos e desencadeiam associações. Isso ocorre, por exemplo, no momento em que Eduardo encontra o coronel Vianna pela primeira vez e o acha parecido com o ator Rock Hudson. 0 resultado é um exercício de linguagens que se interferem e se sobrepõem impedindo o silêncio, a imobilidade, a cegueira, a morte, enfim. Ocorre que, enquanto se tenta apagar a virtualidade da morte, assim mesmo seu fantasma permanece; 
basta se evocar a lembrança de que as placas dos Bichos permanecem imóveis, se ninguém as move; o texto se conserva mudo, se o leitor não se aventura a dialogar com ele.

Em alguns casos, o leitor se vê capturado numa armadilha, em busca de algum sentido. A relação de Leila e Aníbal ilustra tal situação. 0 casal posa para os outros e o leitor sabe que eles não se comunicam. Nessa situação, o relacionamento se realiza a distância e a falta de sentido, aqui, faz sentido. Seu contato íntimo somente ocorre de longe e ambos retiram disso o seu prazer e estranhamente continuam juntos, respeitando uma espécie de pacto. 0 caso é perceber que essa estratégia provoca uma sedução sobre o olhar de quem lê, que volta várias vezes ao texto em busca de sentido. Ao mesmo tempo, ele deve manter em mente a impossibilidade de se encontrarem totalidades. Permanece o estado de busca de algum sentido. Personagens e leitores fazem-se vários e buscam.

Por isso, Stella Manhattan é a narrativa de corpos que se deslocam e explicitam o exercício desse deslocamento, enquanto passam por outros corpos. Nos desdobramentos das personagens (e de seus fragmentos) umas nas outras, encontra-se também um narrador que se fragmenta entre aquele que escreve e aquele que lê; o que não se expõe é o desejo de se encontrarem respostas prontas ou receitas para se viver melhor. Vê-se, sim, a busca pelo viver contando-se com o elemento surpresa, o não-sentido, o imprevisível, momento em que o leitor também se vê inscrito naquele espaço ficcional, comungando e celebrando com personagens e narradores palavras, imagens e corpos, sobretudo.

Pelo menos três semas permeiam os Bichos e as bonecas de Bellmer (obras às quais Silviano Santiago dedica Stella Manhattan): brinquedo, jogo, máquina. São objetos reversíveis, entregues à percepção de quem os manipula ou os observa. Mesmo distantes, concentram diversos aspectos. Não contêm referência temporal, o que os torna vinculados a um agora materializado no momento do encontro, seja para manipulálos, seja para observá-los. Ainda que encerrados num museu, não pertencem necessariamente a um passado, a uma cultura específica - são ao mesmo tempo conectados à definição dada pelo observador e soltos de vínculos específicos que possam encerrá-los em um significado totalizador. 


\section{EMTESE}

Belo Horizonte, v. 9, p. I-28I, dez. 2005

Por isso, para Silviano Santiago, não há problema em expor a intimidade do processo de construção do romance, que se metamorfoseia nos Bichos e nas bonecas de Bellmer. Retornando à parte denominada "Começo: o Narrador", a mão que escreve confessa: "Você continua a rir de mim e eu pensando como são falsos os romances que só transmitem a continuidade da ação, mas nunca transmitem a descontinuidade da criação".

Observando-se a construção do romance e a entrevista mencionada com o autor, conclui-se que a metáfora da dobradiça remete o sujeito contemporâneo ao desafio da multiplicidade. Trata-se de um desafio no momento em que se reconhece a impossibilidade e a impraticabilidade do uno. Reconhecer a multiplicidade é também dizer um sim à vida, admitir o desejo, renunciar à busca do uno e da verdade e assumir a vivência do agora permeado por todos os tempos e também, por sua vez, gerador deles. Se o caso é aprender com o agora múltiplo, cabe, da mesma forma, aprender a viver e desejar plenamente, como ensina e encena Stella, a qual, ainda que Manhattan, é um pouco de todos e de todas, dos Bichos e das bonecas de Bel1mer, um pouco dos diversos universos que compõem a vida humana.

0 tratamento dado às idéias de dobradiça e dobradura oscila entre a instabilidade do signo, mencionada por Hal1: "0 significado é inerentemente instável: ele procura o fechamento (a identidade), mas ele é constantemente perturbado (pela diferença)". As personagens de Stella Manhattan, nomeadas pelo próprio autor do romance como dobradiças, permanecem na instabilidade e na abertura, apresentam-se como rizoma, tendendo à expansão. Nesse romance, as personagens encenam a realização do desejo, que abole a moral e a censura, abrindo caminho e se expandindo em direção a seu objetivo - sua realização. 0 futuro não é problema; importa viver o presente como um ponto de encontro entre passado e futuro.

Em Brazil, inicialmente, tudo parece caminhar para um rompimento com o status quo. Isabel e Tristão abandonam as famílias e lutam para se manterem juntos. Chegam ao ponto de trocar de cor de pele. No entanto, as diferenças - e, portanto, as barreiras - continuam. Ambos voltam, aceitam ajuda do pai e do tio de Isabel, acomodam-se à nova vida fútil da elite paulista, seguindo habilmente o jogo das aparências sociais. 0 projeto tende ao fracasso, pois a mudança é aparente, o movimento caminha para o ponto onde tudo começou; trata-se de uma dobradura. A cor do papel muda, entretanto a diferença permanece, cristaliza-se, sem apresentar 
nenhuma possibilidade de mudança. Isabel não pode ter filhos de Tristão, carregando em seu próprio corpo uma barreira para a interação completa de ambos. Esse impedimento de uma mescla dos dois, a qual levaria ao coroamento de sua luta por permanecerem juntos, seria a metáfora mais adequada para se explicitar a permanência de uma crença na impossibilidade de superação das diferenças, enquanto Stella Manhattan insiste em zombar dos limites desse impasse.

ABSTRACT :

This work investigates the hinge-like characters from Stella Manhattan and the folded characters from Brazil. They are considered contemporary world reading strategies.

KEY WORDS: Hinge-like characters, folded characters, globalization, stereotypes, diaspora.

REFERÊNCIAS BIBLIOGRÁFICAS

SANTIAgo, Silviano. Stella Manhattan. 2. ed. Rio de Janeiro: Rocco, 1991.

UPDIKE, John. Brazil. Trad. Marcos Santarrita. São Paulo: Companhia das Letras. 1994. 